\title{
Phase-Boundary Catalysts for Acid-Catalyzed Reactions: The Role of Bimodal Amphiphilic Structure and Location of Active Sites
}

\author{
Hadi Nur ${ }^{*, a}$, Shigeru Ikeda ${ }^{b}$ and Bunsho Ohtani ${ }^{b}$ \\ ${ }^{a}$ Ibnu Sina Institute for Fundamental Science Studies, Universiti Teknologi Malaysia, 81310 UTM Skudai, Johor, \\ Malaysia \\ ${ }^{b}$ Catalysis Research Center, Hokkaido University, Sapporo 060-0811, Japan
}

\begin{abstract}
O potencial catalítico para reações de interface de fases em reações catalisadas por ácidos foi demonstrado pelo zeólito $\mathrm{NaY}$ enriquecido com ácido nióbico recoberto por alquilsilano na reação de hidratação do 1,2-epoxioctano com água em fase líquida. O catalisador foi preparado através da impregnação do ácido nióbico na superfície externa de $\mathrm{NaY}$, seguida da modificação parcial da superfície externa de $\mathrm{NaY}$ com grupos alquilsilanos. As partículas adicionadas a uma mistura contendo água e 1,2-epoxioctano foram facilmente localizadas na interface das fases líquido-líquido, e catalisaram eficientemente a hidratação do epóxido, mesmo sem agitação. Com o objetivo de investigar o efeito da localização dos sítios ativos, foram preparados HZSM-5 alquilsililado e NaY funcionalizado com ácido sulfônico, em que os sítios ativos estão localizados predominantemente na superfície interna dos zeólitos. Neste caso, foi necessária agitação mecânica para aumentar a velocidade de reação. Sugere-se que a alquisilação da superfície externa do zeólito, quando o sítio ativo se encontra principalmente dentro do poro, não pode modificar o modo de ação do catalisador; ainda é necessário agitar a mistura reacional para promover a transferência de massas de substratos e reagentes.
\end{abstract}

The catalytic potential of phase-boundary catalyst for acid-catalyzed reactions has been demonstrated by $\mathrm{NaY}$ zeolite loaded with alkylsilane-covered niobic acid in the liquid phase hydration of 1,2-epoxyoctane with water. The catalyst was prepared by impregnation of niobic acid on the external surface of $\mathrm{NaY}$ and followed by a partial modification of the external surface of $\mathrm{NaY}$ with alkylsilyl groups. When the particles were added to a mixture of water and 1,2-epoxyoctane, they were feasibly located just at the liquid-liquid phase boundary and efficiently catalyzed hydration of the epoxide even without stirring. In order to investigate the effect of the location of the active sites, alkylsilylated HZSM-5 and sulfonic acid functionalized $\mathrm{NaY}$ in which the active sites are located dominantly on the internal surface of zeolites were prepared. In that case, mechanical stirring was needed to increase the reaction rate. It was suggested that alkylsilylation on the external surface of zeolite, when the active site is mainly inside the pore, could not change the mode of the catalytic action; it is still necessary to stir the reaction mixture to drive the mass transfer of substrates and reagents.

Keywords: phase-boundary catalysis, acid-catalyzed reactions

\section{Introduction}

The fast-growing insight into green chemistry has led the research to focus in the area of environmentally benign catalysts. ${ }^{1,2}$ Along this line, we recently reported a novel concept of the "phase-boundary catalysis (PBC)"3-6 in order to utilize an immiscible liquid-liquid system using a solid catalyst. Several authors have reported such triphase system in which the homogeneous modification of a particulate

* e-mail: hadi@kimia.fs.utm.my catalyst loaded with metal ions or their complexes as active sites induced or accelerated the catalytic reaction of organic substrate with aqueous solution. ${ }^{7,8}$ In such triphase systems, however, vigorous stirring, leading to sufficient mass transfer, is required to drive the reaction. Another important concept in order to utilize an immiscible liquidliquid system is "phase-transfer catalysis". The term, "phase-transfer catalysis", was originally introduced by Starks to characterize a process in which: "reaction is brought about the use one reactant across the interphase into the other phase so that reaction can proceed". ${ }^{9}$ In this 
system, the agitation is also needed to mechanically shuttle the catalyst from one liquid phase to the other. Our strategy is different from those previously reported because we aim at placing the bifunctional particles, containing both hydrophilic and hydrophobic regions, as well as the active sites at the phase boundary in order to catalyze the reaction without any transports the substrate across the interphase and without the formation of an emulsion containing a catalyst by vigorous stirring. Proposed model of phaseboundary catalyst is shown in Figure 1. This system offers advantages in terms of ease of separation, the possibility of continuous supply of immiscible substrates and working effectively without co-solvent. This phenomenon was observed when the external surface of zeolites is covered partially with hydrophobic alkylsilyl groups.

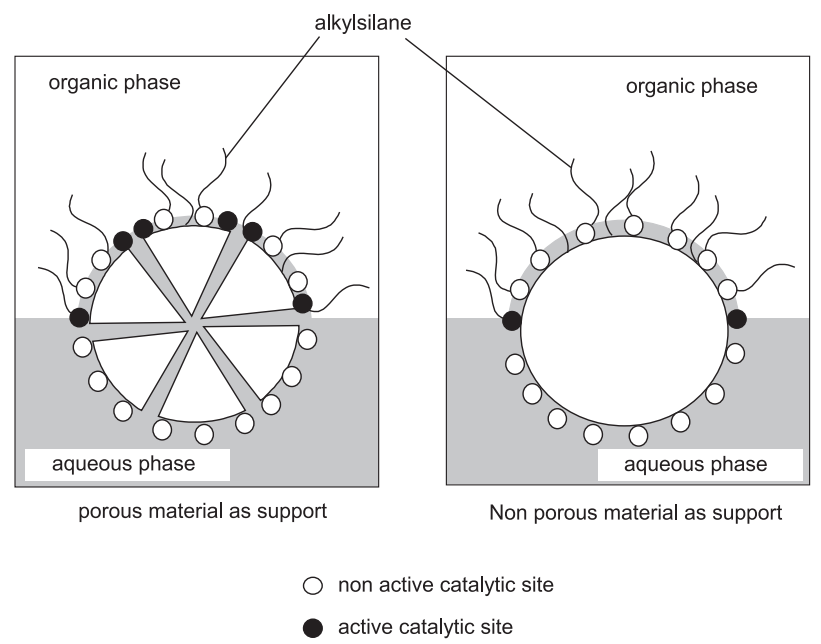

Figure 1. Proposed model of phase-boundary catalyst.

Previously, we reported the PBC for the oxidation reactions using aqueous $\mathrm{H}_{2} \mathrm{O}_{2}$. In this paper, the study of $\mathrm{PBC}$ is now extended for acid catalysis in which the hydration of 1,2-epoxyoctane using zeolite loaded niobium oxide covered by alkylsilane is chosen as model catalytic system.

\section{Experimental}

\section{Catalysts preparation}

Alkylsilylated HZSM-5. HZSM-5 (JRC-Z5-90H(1)) powder was supplied by the Catalysis Society of Japan and used as received. The $\mathrm{SiO}_{2} / \mathrm{Al}_{2} \mathrm{O}_{3}$ ratio and surface area of HZSM-5 were 90 and $300 \mathrm{~m}^{2} \mathrm{~g}^{-1}$ respectively. Unmodified HZSM-5 is called w-HZSM-5. Partly modified ZSM-5 on which the external surface was partly covered with alkylsilane was prepared by attachment of $n$-octadecyltrichlorosilane (ODS). This preparation method is same as given in our recent papers..$^{3-6}$ In a typical experiment, in order to modify HZSM-5 with alkylsilane, the w-HZSM-5 powder containing water $(0.5-0.9 \mathrm{~g}$ per $1.0 \mathrm{~g}$ of $\mathrm{w}-\mathrm{HZSM}-5)$ was immersed in $5 \mathrm{~mL}$ toluene containing $500 \mu \mathrm{mol}$ of $n$-octadecyltrichlorosilane (ODS, ShinEtsu) and the suspension was shaken for $c a .5$ minutes at room temperature. Then, the solid was collected by centrifugation and dried at $383 \mathrm{~K}$ for $5 \mathrm{~h}$. The partly modified sample was labeled w/o-HZSM-5. Fully modified HZSM-5 (o-HZSM-5) was prepared without the addition of water.

Passivation of the external surface of HZSM-5. In the first step, $n$-octadecyltrichlorosilane (ODS) is attached by fully coverage, with a similar procedure for making o-HZSM-5. In the second step, the powders obtained were calcined at $500{ }^{\circ} \mathrm{C}$ for $5 \mathrm{~h}$ in order to make the external surface of HZSM-5 coated by silica layer. The solids obtained were further modified with ODS at a similar procedure in the preparation of w/o-HZSM-5 and o-HZSM-5. They were labeled as w-Si-HZSM-5, w/o-Si-HZSM-5 and o-Si-HZSM-5.

Sulfonic acid functionalized NaY. NaY zeolite (JRCZ-Y5.5) was supplied by the Catalysis Society of Japan and used as received. The $\mathrm{SiO}_{2} / \mathrm{Al}_{2} \mathrm{O}_{3}$ ratio and surface area of $\mathrm{NaY}$ zeolite were 5.5 and $700 \mathrm{~m}^{2} \mathrm{~g}^{-1}$ respectively. Sulfonic acid covered $\mathrm{NaY}$ zeolite was prepared according to the literature. ${ }^{10}$ In typical experiment, before modification, $\mathrm{NaY}$ zeolite is calcined at $400{ }^{\circ} \mathrm{C}$ for $2 \mathrm{~h}$ in order to remove adsorbed water. Calcined $\mathrm{NaY}$ zeolite $(3 \mathrm{~g})$ is added to a solution of 3-mercatopropyl trimethoxysilane (MPTS, Wako) $(0.294 \mathrm{~g})$ dissolved in toluene $(20 \mathrm{~mL})$ as the organosulfonic acid precursor. Toluene was dried over zeolite $4 \mathrm{~A}$ before use. The molar amount of sulfonic acid $\left(\mathrm{SO}_{3} \mathrm{H}\right)$ was $500 \mu \mathrm{mol} \mathrm{g}{ }^{-1}$ zeolite. After $4 \mathrm{~h}$ refluxing, the powder is collected and washed with $\mathrm{CH}_{2} \mathrm{Cl}_{2} / \mathrm{Et}_{2} \mathrm{OH}(1: 1)$ $(50 \mathrm{~mL})$ and air-dried.

Materials with immobilized mercaptopropyl groups were oxidized with $\mathrm{H}_{2} \mathrm{O}_{2}$ in methanol-water mixture. Typically, $6 \mathrm{~mL} \mathrm{30 \%} \mathrm{H}_{2} \mathrm{O}_{2}$ dissolved in $18 \mathrm{~mL}$ methanol. After $24 \mathrm{~h}$, the suspension was filtered, and washed with $\mathrm{H}_{2} \mathrm{O}$ and $\mathrm{EtOH}$. The wet material was resuspended (3 wt $\%$ ) in $0.1 \mathrm{~mol} \mathrm{~L}^{-1} \mathrm{H}_{2} \mathrm{SO}_{4}$ for $2 \mathrm{~h}$. Finally, the materials were extensively rinsed with $\mathrm{H}_{2} \mathrm{O}$ and dried at $333 \mathrm{~K}$ under vacuum. These acid materials are denoted with $\mathrm{SO}_{3} \mathrm{H}-\mathrm{NaY}$.

Partly modified $\mathrm{SO}_{3} \mathrm{H}-\mathrm{NaY}$ in which the external surface was partly covered with alkylsilane from ODS was prepared with the same procedure for making w/o-HZSM-5 and labeled as w/o- $\mathrm{SO}_{3} \mathrm{H}-\mathrm{NaY}$. Unmodified and fully modified $\mathrm{SO}_{3} \mathrm{H}-\mathrm{NaY}$ were labeled as w-SO $\mathrm{S}_{3} \mathrm{H}-\mathrm{NaY}$ and o- $\mathrm{SO}_{3} \mathrm{H}-\mathrm{NaY}$ respectively.

Niobic acid functionalized $\mathrm{NaY}$. NaY zeolite covered niobic acid ( $\mathrm{Nb}-\mathrm{NaY})$ was prepared by impregnation of 
niobium pentaethoxide $\left(\left[\mathrm{Nb}(\mathrm{OEt})_{5}\right]\right)$ from its ethanol solution at room temperature. The molar amount of $\mathrm{Nb}$ was $500 \mu \mathrm{mol} \mathrm{g}{ }^{-1}$ zeolite. Unmodified $\mathrm{Nb}-\mathrm{NaY}$ is called w-Nb-NaY. Modified Nb-NaY on which the external surface was partly covered with alkylsilane was prepared by attachment of $n$-octadecyltrichlorosilane (ODS). This preparation method is same as given in preparation of alkylsilylated HZSM-5. The partly modified sample was labeled w/o-Nb-NaY and o-Nb-NaY for fully modified.

\section{Reaction conditions}

Hydration of cyclohexene was carried out using the above catalysts. Cyclohexene $(2 \mathrm{~mL})$, water $(2 \mathrm{~mL})$ and catalyst powder $(50 \mathrm{mg})$ were placed in a glass tube, and the reaction was performed with or without stirring at 70 ${ }^{\circ} \mathrm{C}$ for $20 \mathrm{~h}$ after removal of oxygen by argon bubbling. Hydration of 1,2-epoxyoctane with water was carried out at $70{ }^{\circ} \mathrm{C}$ for $20 \mathrm{~h}$. In detail, 1,2-epoxyoctane $(1 \mathrm{~mL})$, water $(1 \mathrm{~mL})$ and catalyst powder $(25 \mathrm{mg})$ were placed in a glass tube, and the reaction was performed with or without stirring. The reaction products of the above reactions were analyzed by gas chromatography (Shimadzu GC-14B with FID and DB-1 column) and GC/MS.

\section{Results and Discussion}

\section{Effect of stirring on the location of active sites}

Figure 2 shows the yield of cyclohexanol in the hydration of cyclohexene with water over w-HZSM-5, w/o-HZSM-5 and o-HZSM-5. The first effect observed from this figure is that the stirring is required to increase the reaction rate. Our early results in the epoxidation reactions ${ }^{3-5}$ indicate no mass transfer limitation observed when the active sites were located on the external surface of zeolite

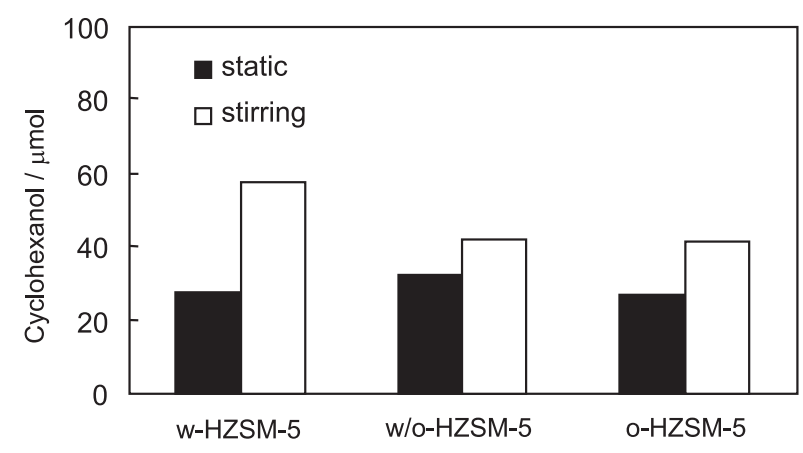

Figure 2. The yield of cyclohexanol in organic phase on the hydration of cyclohexene using various modified HZSM-5 under static and stirring conditions. All reactions were carried out at $70{ }^{\circ} \mathrm{C}$ in argon atmosphere for $20 \mathrm{~h}$ : $50 \mathrm{mg}$ catalyst; $2 \mathrm{~mL}$ cyclohexene and $2 \mathrm{~mL}$ water. and the catalyst particles were placed at the liquid-liquid boundary, therefore we conclude that the activity of catalyst does not depend on the stirring rate. On the other hand, this phenomenon could not be applied for hydration of cyclohexene by w/o-HZSM-5 even though the catalyst was successfully placed at the liquid-liquid boundary. Furthermore, diffusion resistance becomes dominant factor in this triphasic mode reaction. This can be explained on the basis of the location of active sites of HZSM-5, which are located predominantly inside the pore, and not on the external surface. Based on this consideration, the role of the external active sites in the reaction could be examined by passivating the external surface of zeolite with silica layer coating, where this layer has been considered not to be active for hydration of cyclohexene. Figure 3 shows the trend of the catalytic activity of w-Si-HZSM-5, w/o-Si-HZSM-5 and o-Si-HZSM-5 (passivated HZSM-5s). Although the results show no significant effect of this approach for the trend of catalysts' activities, under static conditions, the yield of passivated HZSM-5 exhibit a yield ca. 5\% lower when compared to unpassivated HZSM-5. This suggests that the active sites located on the external surface give a contribution for increasing the catalysts' activity under static conditions, although their contribution to the overall reaction is small.

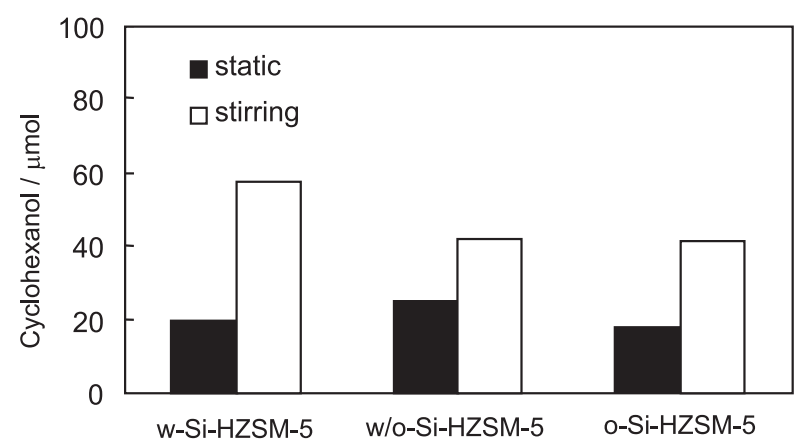

Figure 3. The yield of cyclohexanol in organic phase on the hydration of cyclohexene using various modified HZSM-5 under static and stirring conditions. Reaction conditions are the same as given for Figure 2.

\section{Nature of active sites}

Catalytic activities as depicted in Figures 2 and 3 indicate w-HZSM-5 is the most active catalyst for hydration of cyclohexene. In our previous reports, ${ }^{3-5}$ it was explained that the highest catalytic activity has a correlation to the location of catalysts' particles, in which the solid catalyst was placed at the liquid-liquid phase boundary. Obviously, this argument does not hold for the w-HZSM-5 since the enhancement of the rate cannot be solely attributed to the distribution of catalysts in liquid- 
liquid system and location of their active sites. The effect of HZSM-5 intrinsic properties such as the existence of active sites in the framework and its MFI structure play an important role in the catalytic activity. These properties certainly give a synergy effect for the catalytic activities with hydrocarbons. ${ }^{11}$ To exclude the possibility of these characteristics, sulfonic acid $\left(\mathrm{SO}_{3} \mathrm{H}\right)$ anchored on the surface of $\mathrm{NaY}$ zeolite was used as a catalyst model. Since the molecular size of MPTS ( $c a .0 .55 \mathrm{~nm}$ ) is smaller than pore size of $\mathrm{NaY}$ zeolite $(\mathrm{ca} .0 .70 \mathrm{~nm})$, it is expected that the deposition of $\mathrm{SO}_{3} \mathrm{H}$ occur on the internal surface of zeolite. This catalyst was used for acid catalysis in the system containing cyclohexene and water.

As shown in Figure 4, all the systems containing modified sulfonic acid functionalized zeolites (w-SO $\mathrm{H}-\mathrm{NaY}$, w/o- $\mathrm{SO}_{3} \mathrm{H}-\mathrm{NaY}$ and $\mathrm{o}-\mathrm{SO}_{3} \mathrm{H}-\mathrm{NaY}$ ) produce 2-methyl-2cyclopenten-1-one as a major product as analyzed by GC/MS. A similar compound was also observed when $0.1 \mathrm{~mol} \mathrm{~L}^{-1} \mathrm{H}_{2} \mathrm{SO}_{4}$ was used instead of those catalysts in the same experimental conditions (Figure 4). With a w/o- $\mathrm{SO}_{3} \mathrm{H}-\mathrm{NaY}$, under stirring conditions, the activity (i.e., the peak area of the 2-methyl-2-cyclopenten-1-one per amount of $\mathrm{SO}_{3} \mathrm{H}$ ) more than triples compared to the mixture containing $\mathrm{H}_{2} \mathrm{SO}_{4}$. This indicates that the w/o- $\mathrm{SO}_{3} \mathrm{H}-\mathrm{NaY}$ is particularly capable of catalyzing the reaction at the liquid-liquid phase-boundary. However, the mechanism of this reaction was not fully understood. It could be that the carbenium ion and ring contraction occur within the mechanisms. ${ }^{12,13}$ In order to investigate heterogeneity, the catalysts were suspended in water and stirred for $2 \mathrm{~h}$ at $70{ }^{\circ} \mathrm{C}$. After filtration, the water, without the catalyst, was vigorously stirred for $20 \mathrm{~h}$ with addition of cyclohexene. This system exhibits no activity suggesting the reaction occurs on the catalyst particles, but not due to the leached $\mathrm{SO}_{3} \mathrm{H}$ species. It should be noted that the mass transfer limitations may be place a constraint on $\mathrm{SO}_{3} \mathrm{H}-\mathrm{NaY}$ catalysis because of the location of $\mathrm{SO}_{3} \mathrm{H}$ is mainly inside
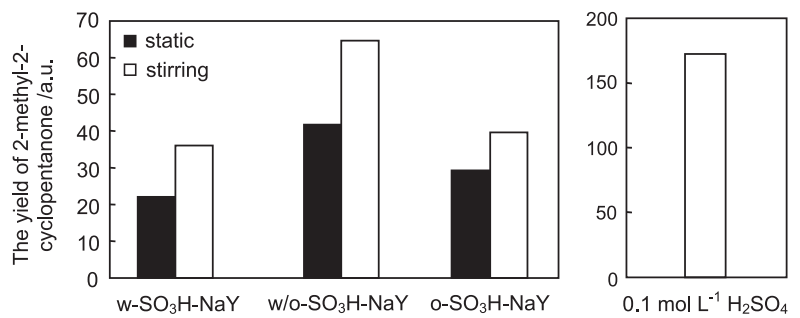

Figure 4. The yield of 2-methyl-2-cyclopenten-1-one in organic phase on the reaction of cyclohexene with water using various modified $\mathrm{SO}_{3}-\mathrm{NaY}$, under static and stirring conditions. Due to lack of the authentic sample, the yield was calculated from the peak area of 2methyl-2-cyclopentene-1-one in chromatogram. Reaction was also carried out with acidified aqueous phase $\left(0.1 \mathrm{~mol} \mathrm{~L}^{-1} \mathrm{H}_{2} \mathrm{SO}_{4}\right)$. Reaction conditions are the same as given for Figure 2. the pore of NaY. It is clearly shown in Figure 4 that these mass transfers are further enhanced by the mechanical agitation. For comparison, modified $\mathrm{SO}_{3} \mathrm{H}-\mathrm{NaY}$ catalysts were also used to catalyze the hydration of 1,2-epoxyoctane to 1,2-octanediol, and the results are shown in Figure 5. It showed that the activity of modified $\mathrm{SO}_{3} \mathrm{H}-\mathrm{NaY}$ was also always higher when mechanical agitation was applied for the system. Similar to the hydration of cyclohexene (Figure 3 ), the results in Figure 5 showed that w/o- $\mathrm{SO}_{3} \mathrm{H}-\mathrm{NaY}$ also gave a higher activity compared to $\mathrm{w}-\mathrm{SO}_{3} \mathrm{H}-\mathrm{NaY}$ and $\mathrm{o}-\mathrm{SO}_{3} \mathrm{H}-\mathrm{NaY}$. One possible explanation is that the bimodal amphiphilicity character of w/o- $\mathrm{SO}_{3} \mathrm{H}-\mathrm{NaY}$ gives a large contribution to the catalytic activity. This argument was supported by the distribution of catalysts during the reaction under static conditions; w/o- $\mathrm{SO}_{3} \mathrm{H}-\mathrm{NaY}$ was located at the liquid-liquid phase boundary, whereas w-SO $\mathrm{SO}_{3} \mathrm{H}-\mathrm{NaY}$ and o- $\mathrm{SO}_{3} \mathrm{H}-\mathrm{NaY}$ were dispersed in aqueous and organic phases respectively.

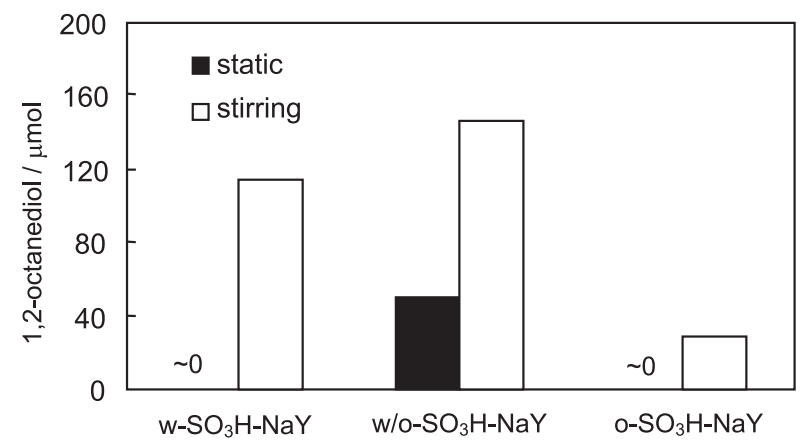

Figure 5. The yield of 1,2-octanediol in organic and aqueous phases on the hydration of 1,2-epoxyoctane using various modified $\mathrm{SO}_{3} \mathrm{H}$ $\mathrm{NaY}$ under static and stirring conditions. All reactions were carried out at $70{ }^{\circ} \mathrm{C}$ for $20 \mathrm{~h}$ : $25 \mathrm{mg}$ catalyst; $1 \mathrm{~mL} \mathrm{1,2-epoxyoctane} \mathrm{and} 1$ $\mathrm{mL}$ water. The yield was subtracted from the control experiment, without catalyst.

\section{Niobic acid functionalized $\mathrm{NaY}$}

According to the catalytic activity of the alkylsilylated HZSM-5 and sulfonic acid functionalized NaY as catalyst models of acid-catalyzed reactions, the specific role of location and nature of the active sites was examined. The two effects may indeed account for the observed catalytic activity of the catalysts in the liquid-liquid system under static and stirring conditions. Thus, our task here is to confirm the effect of active site which is located at the external surface of zeolite. Based on this purpose, niobic acid functionalized $\mathrm{NaY}$ has been chosen as another catalyst model. Although there is no experimental evidence at present, $\mathrm{Nb}$ active sites should be attached to the external surface of $\mathrm{NaY}$ since the estimated molecular size of $\mathrm{Nb}\left(\mathrm{OC}_{2} \mathrm{H}_{5}\right)_{5}(\mathrm{ca} .0 .90 \mathrm{~nm})$, the source of $\mathrm{Nb}$ sites, larger than the size of pore-entrance of NaY $(c a .0 .70 \mathrm{~nm})$. 
The dispersion behavior of w/o-Nb-NaY, prepared with different amount of added water to form $\mathrm{Nb}-\mathrm{NaY}$ aggregates before attachment of alkyl groups, and o-Nb-NaY are shown in Figure 6. From their dispersibility, more water is added to $\mathrm{Nb}-\mathrm{NaY}$, resulting more hydrophilic w/o-Nb-NaY particles. It was found that the addition of $c a$. $60-70 \mathrm{wt} \%$ water per $\mathrm{g} \mathrm{Nb}-\mathrm{NaY}$ gave the highest yield of 1,2-octanediol. Addition of more than $90 \mathrm{wt} \%$ water per $\mathrm{g}$ $\mathrm{Nb}-\mathrm{NaY}$ can make the powder totally wetted by water in the form of 'wet cake'. After attachment of alkylsilyl groups, the resulting alkylsilylated particles seemed heterogeneous; some particles were located at the phaseboundary while others were dispersed in water.

It should be noted that alkylsilyl groups should be attached to the external surface of $\mathrm{NaY}$ zeolite since the estimated molecular size of alkylsilane ( $c a .0 .50 \mathrm{~nm}$ x 2.60 $\mathrm{nm}$ ), the source of alkylsilyl, larger than the size of poreentrance of NaY zeolite $(c a .0 .70 \mathrm{~nm})$. The distribution of alkylsilyl groups on the external surface of w/o-NaY has been clarified by using fluorescence microscopy; each w/o-NaY particle has both hydrophobic and hydrophilic surfaces; i.e., one side is covered with alkylsilyl groups and the other is kept covered with hydroxyl groups (silanols). Details for this fluorescence microscopic study was reported recently. ${ }^{5}$ Because of this surface characteristic, the modified particles are spontaneously located at the interphase in a W/O mixture with the hydrophobic side facing the organic phase and the hydrophilic side facing the aqueous phase.

As demonstrated in the previous paper, ${ }^{4}$ in the water adsorption experiment, it was observed that the adsorption capacity of OTS-modified NaY particles at ambient temperature $\left(8 \mathrm{mmol} \mathrm{g}^{-1}\right.$ for both w/o-NaY and o-NaY) (c)

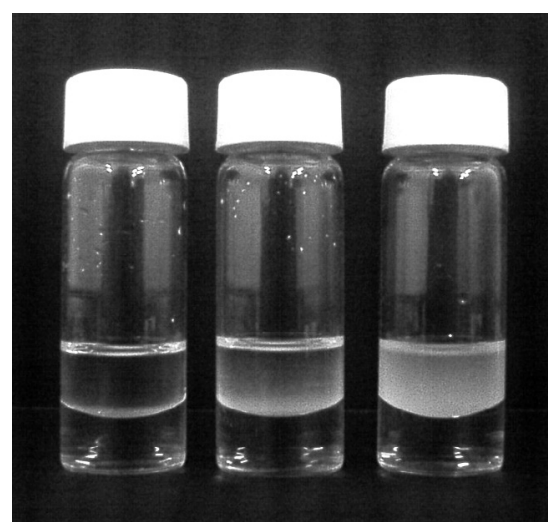

Figure 6. The distribution of various modified $\mathrm{Nb}-\mathrm{NaY}$ in the mixture of 1,2-epoxyoctane and water: (a) o-Nb-NaY; (b) w/o-Nb-NaY with the amount of added water to form $\mathrm{Nb}-\mathrm{NaY}$ aggregates before attachment of ODS is $88 \%$ wt water per $\mathrm{g} \mathrm{Nb}-\mathrm{NaY}$ and (c) $50 \%$ wt water per g Nb-NaY. was not so different from that of the parent $\mathrm{NaY}$ zeolite $\left(11 \mathrm{mmol} \mathrm{g}^{-1}\right)$, indicating that the structure and hydrophilic features of internal pores of these $\mathrm{NaY}$ particles were retained and that the hydrophobic alkyl chains did not block the entrance of zeolite pores.

When the above catalysts were used in reaction system containing 1,2-epoxyoctane and water, it was observed that, after four hours reaction, under stirring condition, the emulsion was formed in the system containing w/o-Nb-NaY, whereas o-Nb-NaY was still located at organic phase due to its hydrophobicity in nature (Figure 7). Instead distinctly, the w-Nb-NaY was well dispersed in aqueous phase. This suggests that w/o-Nb-NaY possess amphiphilic character to stabilize the immiscible mixture of organic and aqueous phases.

As shown in Figure 7, all the system containing modified niobic acid functionalized zeolite ( $\mathrm{w}-\mathrm{Nb}-\mathrm{NaY}$, w/o-Nb-NaY and o-Nb-NaY) produced 1,2-octanediol as a major product. The w/o-Nb-NaY gave highest yield of diol in comparison to the w-Nb-NaY and o-Nb-NaY. It is notable that the activity of w/o-Nb-NaY was independent of the stirring rate; i.e., this catalyst does not require the formation of the emulsion by stirring at $c a .1000 \mathrm{rpm}$. One needs to consider that the hydrophilic and hydrophobic parts of the w/o-Nb-NaY play an important role for continuous supply of the organic and aqueous substrates to the active sites, and increase the activity.

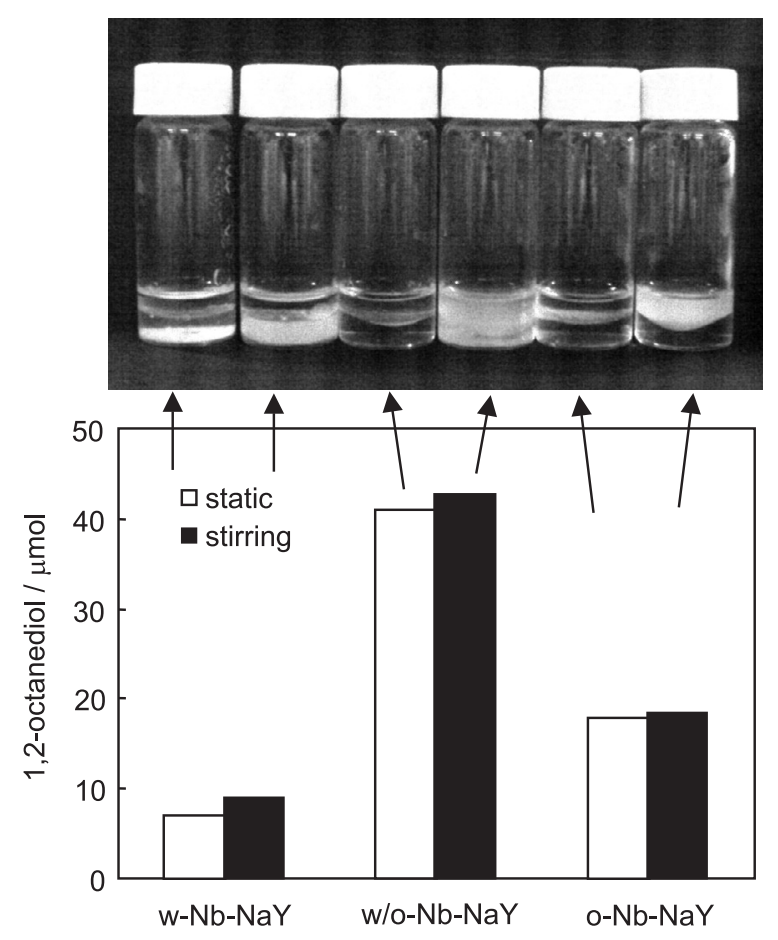

Figure 7. The yield of 1,2-octanediol in organic and aqueous phases on the hydration of 1,2-epoxyoctane using various modified $\mathrm{Nb}$ $\mathrm{NaY}$, under static and stirring conditions. Reaction conditions are the same as given for Figure 5. The photograph shows the distribution of solid catalyst after $4 \mathrm{~h}$ reaction. 
The hydration rate of 1,2-epoxyoctane under static condition is shown in Figure 8. It was observed that the reaction rate was considerably slow. Due to no significant quantitative yield was observed in the first 30 minutes, the reaction was extended to $20 \mathrm{~h}$. It confirms that significant difference in the rate of the reaction between w-Nb-NaY, w/o-Nb-NaY and o-Nb-NaY is observed.

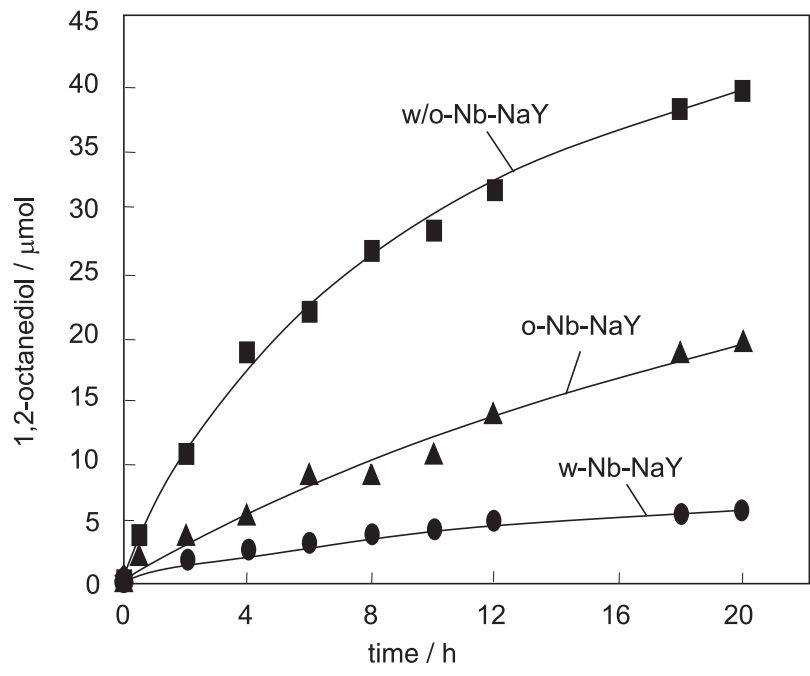

Figure 8. The hydration rate of 1,2-epoxyoctane using various modified $\mathrm{Nb}-\mathrm{NaY}$ under static conditions. Reaction conditions are the same as given for Figure 5.

It has been reported in the previous paper that $\mathrm{NaY}$, having a microporous structure with a relatively large surface area, was preferable as a support in this system compared with nonporous silica with a smaller surface area. ${ }^{4}$ One considers that $\mathrm{Nb}$ active sites on the $\mathrm{NaY}$ surface can be in contact with both organic substrate and water. During the reaction at the $\mathrm{Nb}$ sites, due to the decrease in the concentration of substrate and water at the interphase, the concentration gradient of these reagents may appear in both organic and aqueous phases; this gradient may generate a driving force to supply these reagents from respective bulk solutions, thereby enabling the reaction to proceed efficiently without any enforced manipulation, such as stirring, in order to drive liquid-liquid mass transfer. In order to achieve this, the catalyst must satisfy the following requirements: (i) existence of active $\mathrm{Nb}$ sites at the liquid-liquid phase boundary, and (ii) continuous supply of both substrates through the hydrophobic and hydrophilic parts of the catalyst particles. Therefore, if the catalyst particles consist of nonporous materials, the number of $\mathrm{Nb}$ active sites are limited and efficient $\mathrm{PBC}$ cannot be expected (see Figure 1). The use of a microporous material as a support must increase the effective interphase area of the catalyst (i.e., increase the number of active sites), resulting in higher activity.
Attachment of aklylsilane on the niobic acid sites is another possibility cause lowering activity of o-Nb-NaY compared to w/o-Nb-NaY. In order to exclude this argument, the Temperature Programme Desorption (TPD) of ammonia experiments were performed on $\mathrm{w}-\mathrm{Nb}-\mathrm{NaY}$, w/o-Nb-NaY and o-Nb-NaY. It was observed that no significant difference in the amount of acid sites from calculation of desorbed ammonia amount within the samples. ${ }^{14}$ This suggests that the acid sites on the modified samples are not attached by ODS.

\section{Conclusions}

In this study, the phase-boundary catalysis concept was applied for acid-catalyzed hydration of 1,2-epoxyoctane with water by $\mathrm{NaY}$ zeolite loaded with alkylsilane-covered niobic acid. This system did not require stirring to make an emulsion to drive the hydration. The nature of acid sites and their location, whether in the pore or on the external surface of zeolite, are important factors for the catalytic activity of phase-boundary catalysts for acid catalysis.

\section{References}

1. Matlack, A. S.; Introduction to Green Chemistry, Marcel Dekker: New York, 2001

2. Clark, J. H.; Macquarrie, D. J.; Chem. Commun. 1998, 853.

3. Nur, H.; Ikeda, S.; Ohtani, B.; Chem. Commun. 2000, 2235.

4. Nur, H.; Ikeda, S.; Ohtani, B.; J. Catal. 2001, 204, 402.

5. Ikeda, S.; Nur, H.; Sawadaishi, T.; Ijiro, K.; Shimomura, M.; Ohtani, B.; Langmuir 2001, 17, 7976.

6. Ikeda, S.; Nur, H.; Wu, P.; Tatsumi, T.; Ohtani, B.: Stud. Surf. Sci. Catal. 2003, 145, 251.

7. Tatsumi, T.; Koyano, K. A.; Igarashi, N.; Chem. Commun. 1998, 325.

8. D’Amore, M. B.; Schwarz, S.; Chem. Commun. 1999, 121.

9. Starks, C. M.; J. Am. Chem. Soc. 1971, 93, 195.

10. Bossaert, W. D.; De Vos, D. E.; Van Rhijn, W. M.; Bullen, J.; Grobet, P. J.; Jacobs, P. A.; J. Catal. 1999, 182, 156.

11. van Bekkum, H.; Flanigen, E. M.; Jansen, J. C., eds.; Introduction to Zeolite Science and Practice, Elsevier Science: Amsterdam, 1991

12. March, J.; Advanced Organic Chemistry, $3^{\text {rd }}$ edition, John Wiley and Sons: New York, 1985.

13. Kazansky, V. B.; Catal. Rev. 2001, 43, 199.

14. Nur, H.; Hau, N. Y.; Muhid, M. N. M.; Hamdan. H.; unpublished work.

Received: September 22, 2003

Published on the web: September 9, 2004 